\title{
Cellulose-Silica Nanocomposites of High Reinforcing Content with Fungi Decay Resistance by One-Pot Synthesis
}

\author{
M. Concepción Rodríguez-Robledo ${ }^{1}$, M. Azucena González-Lozano ${ }^{2}$, Patricia Ponce-Peña ${ }^{2}$, \\ Patricia Quintana Owen ${ }^{3}$, Miguel Angel Aguilar-González ${ }^{4}$, Georgina Nieto-Castañeda ${ }^{4}$, \\ Elva Bazán-Mora ${ }^{5}$ (i), Rubén López-Martínez ${ }^{5}$, Guillermo Ramírez-Galicia ${ }^{1}$ and \\ Martha Poisot 1,* \\ 1 Universidad del Papaloapan, Circuito Central 200, Parque Industrial, Tuxtepec 68301, Mexico; \\ mc.r.robledo@gmail.com (M.C.R.-R.); memorgal@gmail.com (G.R.-G.) \\ 2 Universidad Juárez del Estado de Durango, Facultad de Ciencias Químicas. Av. Veterinaria S/N, \\ Circuito Universitario, Durango 34120, Mexico; mag162001@yahoo.com.mx (M.A.G.-L.); \\ pattyponcep@yahoo.com (P.P.-P.) \\ 3 Laboratorio Nacional de Nano y Biomateriales, Depto. de Física Aplicada, CINVESTAV Mérida, \\ km 6 Ant. Carr. a Progreso, Mérida 97310, Mexico; p-quint@cinvestav.mx \\ 4 Facultad de Ciencias, Universidad Nacional Autónoma de México, Circuito Interior, Ciudad Universitaria, \\ CdMx 04510, Mexico; hermescurtus@ciencias.unam.mx (M.A.A.-G.); georginanieto@hotmail.com (G.N.-C.) \\ 5 Departamento de Microbiología y Parasitología, Facultad de Medicina, \\ Universidad Nacional Autónoma de México, CdMx 04510, Mexico; elvabm@gmail.com (E.B.-M.); \\ rlm@unam.mx (R.L.-M.) \\ * Correspondence: mpoisot@unpa.edu.mx; Tel.: +52-287-875-9240 (ext. 230)
}

Received: 5 March 2018; Accepted: 29 March 2018; Published: 9 April 2018

\begin{abstract}
Hybrid bionanocomposites based on cellulose matrix, with silica nanoparticles as reinforcers, were prepared by one-pot synthesis of cellulose surface modified by solvent exchange method to keep the biopolymer net void for hosting inorganic nanoparticles. Neither expensive inorganic-particle precursors nor crosslinker agents or catalysts were used for effective dispersion of reinforcer concentration up to $50 \mathrm{wt} \%$. Scanning electron microscopy of the nanocomposites shows homogeneous dispersion of reinforcers in the surface modified cellulose matrix. The FTIR spectra demonstrated the cellulose features even at 50 weight percent content of silica nanoparticles. Such a high content of silica provides high thermal stability to composites, as seen by TGA-DSC. The fungi decay resistance to Trametes versicolor was measured by standard test showing good resistance even with no addition of antifungal agents. This one-pot synthesis of biobased hybrid materials represents an excellent way for industrial production of high performance materials, with a high content of inorganic nanoparticles, for a wide variety of applications.
\end{abstract}

Keywords: nanocomposites; hybrid materials; one-pot synthesis; thermal stability; fungi decay resistance

\section{Introduction}

A composite material is obtained by the combination of two or more chemically distinguishable initial components that shows a significant proportion of the raw materials' properties, thereby delivering a better combination of properties according to the principle of combined action. The continuous phase is called the matrix, while the discontinuous one is known as the reinforcer [1]. The matrix material can be metal, ceramic or polymer, while the reinforcer can be a particle, fiber or sheet [2]. 
Among sustainable materials, natural fiber composites have such advantages as low cost, light weight, comparable specific strength and stiffness to traditional fiber composites, being renewable and possessing formability with low investment, as well as being environmental friendly [3].

Cellulose fibers have been commonly used for reinforcement of polymer matrix composites that must face several incompatibility problems in order to design an optimal material $[4,5]$.

A vital role that determines such composites performance is the interfacial bonding between fiber and matrix. Usually, the plant-based fiber composite shows limited interaction between the hydrophylic fibers and matrices of common hydrophobic nature that allows poor interfacial bonding affecting the mechanical performance negatively and reducing moisture resistance that drives long term properties [6].

The interfacial bonding can be achieved in several ways, including mechanical interlocking, electrostatic bonding, inter-diffusion bonding and chemical bonding $[7,8]$. The latter is of particular importance since it delivers strong improvement of composite performance and such a strategy can be applied to the fiber or the matrix. The chemical approach includes treatments of alkali, acetyl, silane, benzyl, acryl, permanganate, peroxide, isocyanate, titanate, zirconate and acrylonitrile reactions plus maleated anhydride grafted coupling agent, but enzyme treatments are becoming more popular due to environmental concerns $[9,10]$.

Several aerogels of cellulose-silica nanocomposites were prepared by sol-gel method application. The in situ formation of silica in the cellulose gel was obtained with tetraethyl orthosilicate (TEOS) precursor and drying with supercritical $\mathrm{CO}_{2}$ was required for conversion of composite to aerogel [11]. While another working group approach to prepare aerogels involved methoxytrimethylsilane (MTMS) as silica precursor, the aerogel was obtained by using a freeze dryer [12]. Both reports are very successful but also very energy demanding and time consuming, since several days are required to reach the product. Another group prepared organic-inorganic hybrids of cellulose-silica incorporated with polyhedral oligomeric silsesquioxanes (POSS) by using $\gamma$-aminopropyltriethoxy silane ( $\gamma$-APTES) as a crosslinking agent. Even though the POSS amine particles are well dispersed at the nanometer scale throughout the cellulose matrix, this method is costly [13].

In order to obtain composite materials by an accessible and low-cost method, we have adapted the percolating approach of the solvent exchange method applied to nanofibers of cellulose that involve first forming a three-dimensional template through a self-assembly of the fibers, then filling the percolating architecture with a selected polymer. Before this method, it was impossible to incorporate cellulose particles into nonpolar polymers without the use of surfactants or chemical modifications $[14,15]$.

This work strategy has been employed to avoid using crosslinkers agents and catalysts in order to incorporate the inorganic nanoparticles into the matrix; instead, we used the percolating approach to prepare the surface of cellulose fibers by the solvent-exchange method for effective facial interaction with inorganic particles of hydrophobic behavior, such as nanosilica, to design a new hybrid material of homogenous composition. The main feature of this work is to produce nanocomposites using cellulose as the matrix and not as the reinforcer of any other polymer, with no chemical modifications for interacting with inorganic nanoparticles, following a very facile and cost-effective method. This innovative method significantly reduces the complete synthesis time of the cellulose matrix composites from several days to only a few hours, since it comprises only one step of facile cellulose surface modification. On the other hand, the energy consumed during synthesis is very low and cost-effective, delivering a Trametes versicolor resistance cellulose-based hybrid composite with no antifungal agent added, thereby demonstrating low moisture absorption and high dimensional stability, that also shows improved thermal stability against pristine cellulose.

\section{Materials and Methods}

The nanocomposites synthesis requires the starting precursor materials: silicon dioxide of Aerosil 200, $12 \mathrm{~nm}$ particle size with $200 \mathrm{~m}^{2} / \mathrm{g}$ surface area from EVONIK named ASi and silicon dioxide of $100 \mathrm{~nm}$ from AVAN-nanoSil named NSi; the cellulose fibers of 20 micron, named C20, were provided 
by Aldrich (Saint Louis, MO, USA). The first solvent exchange step was adding water in droplets to the cellulose fibers and gently stirring for $15 \mathrm{~min}$ to get a gel, then ethanol was added in droplets at 1:1 volume ratio. Stirring was maintained more than $1 \mathrm{~h}$, and then the second solvent exchange step was applied, adding acetone in droplets at 1:2 volume ratio according to water volume. At this point, the surface modified cellulose by solvent exchange method can be dried and named AG20, while the as-received cellulose is named C20. Stirring was still maintained for $3 \mathrm{~h}$ more; nanosilica, previously wet with acetone, was added while stirring for $10 \mathrm{~min}$ more and $20 \mathrm{~min}$ of an ultrasound bath of $40 \mathrm{kHz}$ was also applied, taking care that the temperature did not exceed $40^{\circ} \mathrm{C}$. Finally, the resultant dough was dried at $60^{\circ} \mathrm{C}$ in an oven, in order to obtain a fine powder.

The first 8 composite samples were synthesized according to the amounts indicated in Table 1 in order to determine the highest amount of nanosilica that can be uniformly dispersed into the two kinds of matrix prepared: C20 and AG20. There are two main parameters that distinguish these composites; one concerns the kind of matrix: $\mathrm{CP} 1, \mathrm{CP} 2, \mathrm{CP} 11$ and $\mathrm{CP} 12$ contain $\mathrm{C} 20$ while $\mathrm{CP} 3, \mathrm{CP} 4$, $\mathrm{CP} 13$ and CP14 contain AG20. The other parameter is the amount of NSi increased from 25 to 100 in steps of $25 \mathrm{wt} \%$ for every matrix set, giving place to 8 samples in total. In order to determine which one of these matrices can rightly disperse the nanoparticles up to $100 \mathrm{wt} \%, 4$ more samples were synthesized according to Table 1, using only the silica nanoparticles of $12 \mathrm{~nm}, \mathrm{ASi}$, in 75 and $100 \mathrm{wt} \%$, comparing the matrix of C20 in CP19 and CP20 and the matrix of AG20 in CP21 and CP22, in order to observe the influence of such silica nanoparticles on the macro and microstructure and properties of the final composites.

Table 1. Composition and labelling of composites prepared from cellulose matrix.

\begin{tabular}{ccccc}
\hline Constituents wt $\%$ & C20 & AG20 & NSi & ASi \\
\hline CP1 & 100 & 0 & 75 & 0 \\
CP2 & 100 & 0 & 100 & 0 \\
CP11 & 100 & 0 & 25 & 0 \\
CP12 & 100 & 0 & 50 & 0 \\
CP3 & 0 & 100 & 75 & 0 \\
CP4 & 0 & 100 & 100 & 0 \\
CP13 & 0 & 100 & 25 & 0 \\
CP14 & 0 & 100 & 50 & 0 \\
CP19 & 100 & 0 & 0 & 75 \\
CP20 & 100 & 0 & 0 & 100 \\
CP21 & 0 & 100 & 0 & 75 \\
CP22 & 0 & 100 & 0 & 100 \\
\hline
\end{tabular}

The FTIR spectra (Attenuated Total Reflectance mode) were recorded using a Perkin Elmer Spectrum (Akron, OH, USA) 100 with 16 scans per sample. The differential scanning calorimetry (DSC) and thermogravimetric analysis (TGA) were performed simultaneously by TGA-DSC Discovery of TA Instrument (New Castle, DE, USA). TGA was recorded for $50-500{ }^{\circ} \mathrm{C}$ at $10{ }^{\circ} \mathrm{C} / \mathrm{min}$ under air atmosphere, while the DSC was run for $150-550^{\circ} \mathrm{C}$ at $10^{\circ} \mathrm{C} / \mathrm{min}$ under nitrogen atmosphere, but the crucible lid was pierced seven times, allowing the gas to escape. SEM images were registered at high vacuum for secondary electrons with acceleration voltage of 1-5 kV, recorded by field-emission equipment JEOL JSM-7600F (Tokyo, Japan). The sample was dispersed by ultrasound bath in isopropyl alcohol.

The standard test of resistance to Trametes versicolor (CDBB-H-1051) followed the ASTM D-1413-07 test method for wood preservatives by laboratory soil-block cultures [16]. The test-blocks, made of composite, were $2 \mathrm{~cm}$ on each face and were oven-dried and maintained in a desiccator until fungi impregnation. In order to cast such a composite-block, the composite-powder was agglutinated by adding acryl-styren resin Joncryl 1522 from BASF (Ludwigshafen, Germany). For comparison, a second viny-acrylic resin, called QV from POLIMEROS ESPECIALES (Cuautitlán Izcalli, Mexico) 
was applied as a film to cover the test-block surface over selected test blocks. All test-blocks were sterilized. The Malt Agar substrate was prepared with 2\% Malt extract and 1.5\% Agar, while the blind test contained just water and 1.5\% Agar. The soil culture bottles were prepared with a $10 \mathrm{~mm}$ square fungus inoculum section, aged for three weeks, then placed over the wood feeder strip and incubated until it was covered by mycelium. Then these culture bottles were ready to receive the test blocks. After 12 weeks in the incubation room, the calculation of weight loss of every test block was performed according to Equation (1).

$$
\frac{T_{1}-T_{2}}{T_{1}} \times 100
$$

where $T_{1}$ is the initial weight and $T_{2}$ is the final weight.

The inoculum was prepared with $9 \mathrm{~g}$ of fungus mycelium, cultured in Malt-Agar and $81 \mathrm{~mL}$ water. The test-block was cultured with $1 \mathrm{~mL}$ of this solution and no further wood preservative was added.

\section{Results and Discussion}

The synthesis and characterization of the functionalized materials were followed by FTIR.

\subsection{Fourier Transform Infrared Spectroscopy}

The most intense absorption peaks of $\mathrm{C} 20$, Figure 1 , are found in $3342 \mathrm{~cm}^{-1}$ due to $\mathrm{OH}$ frequency region of intramolecular hydrogen bond vibration of secondary alcohol C3-OH. . O5 jointly with the $3277 \mathrm{~cm}^{-1}$ peak due to the similar vibration of C2 secondary alcohol [17], and within the area of $1200-1000 \mathrm{~cm}^{-1}$ several absorption peaks are present due to $\mathrm{C}-\mathrm{O}$ stretching vibrations from the glucose ring skeletal vibration [18].

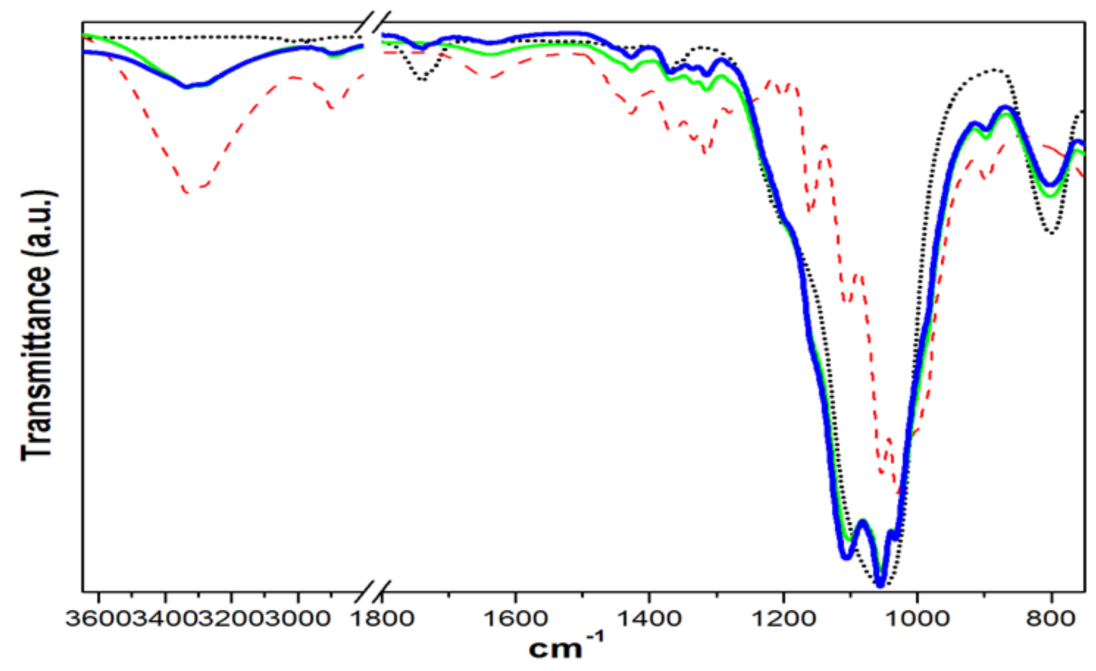

Figure 1. FTIR spectra of C20 (red dash line), NSi (black dot line), CP1 (green line), CP2 (blue line).

The weak antisymmetric vibration of $\mathrm{C}-\mathrm{O}-\mathrm{C}$ is in $1161 \mathrm{~cm}^{-1}$ of the glycoside links, while the $1106 \mathrm{~cm}^{-1}$ vibration is probably due to the $\mathrm{C}-\mathrm{O}$ group which belongs to the same secondary alcohol as the one at the origin of the $\mathrm{OH}$ stretch mode at $3277 \mathrm{~cm}^{-1}$. The most intense band is in $1033 \mathrm{~cm}^{-1}$ due to $\mathrm{C}-\mathrm{O}$ group of $\mathrm{C} 6 \mathrm{H} 2-\mathrm{O} 6 \mathrm{H}$ primary alcohols in dominant conformation, while its secondary conformation is observed in $1000 \mathrm{~cm}^{-1}$. The next band in $1055 \mathrm{~cm}^{-1}$ is due also to C-O group of C3-O3H secondary alcohols [17].

The FTIR spectrum of NSi looks very different from cellulose, Figure 1, since it only shows a very intense band in $1052 \mathrm{~cm}^{-1}$, due to asymmetric mode of Si-O-Si correlated with the next intense band due to symmetric mode of the same $\mathrm{Si}-\mathrm{O}-\mathrm{Si}$ found in $800 \mathrm{~cm}^{-1}$ while the weak band in $1741 \mathrm{~cm}^{-1}$ is related to $\mathrm{C}=\mathrm{O}$ group vibration since NSi is a modified silica [19]. 
On the other hand, the FTIR spectra of composites CP1 and CP2, Figure 1, clearly shows that the band in $1741 \mathrm{~cm}^{-1}$ is only present in $\mathrm{CP} 2$, the composite of equal proportions of cellulose and silica, indicating that the organic matrix is segregating it and it is accepting no more than $43 \mathrm{wt} \%$ of NSi to disperse homogeneously into the fibers of the composite CP1. Such behavior is also observed in Figure 2, showing the scale only from $1800-750 \mathrm{~cm}^{-1}$ for zooming the weakest bands, where the spectrum of $\mathrm{CP} 4$ shows the same band of $1741 \mathrm{~cm}^{-1}$, meaning that the surface modification of pure cellulose to get AG20 is not affecting the fibers capacity to receive and disperse higher amounts of inorganic particles from 43 to $50 \mathrm{wt} \%$.

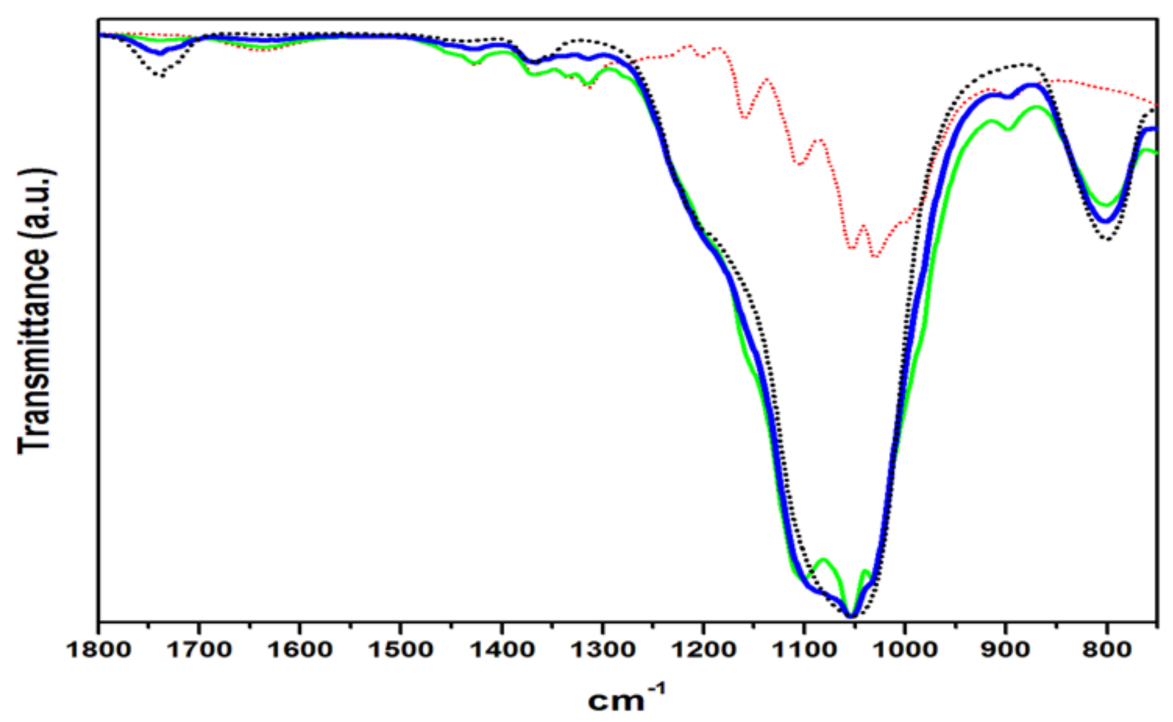

Figure 2. FTIR spectra of AG20 (red dot line), NSi (black dot line), CP3 (green line), CP4 (blue line).

Figure 3 shows the same scale as that of Figure 2, in order to compare the effect of surface modification by solvent exchange method in CP19 up to CP22, when the inorganic particle size is just $12 \mathrm{~nm}$ of ASi. Firstly, ASi shows a weak band in $978 \mathrm{~cm}^{-1}$, such band is absent in NSi. A study of fly ash activation reports an intense band in $989 \mathrm{~cm}^{-1}$ related to $\mathrm{Si}-\mathrm{O}$ asymmetric stretching vibration, which explains that the lower wavenumber of this band was associated with a lower degree of crosslinking of the amorphous phase of silica [20]. The same weak band appears in the composites between 980 and $983 \mathrm{~cm}^{-1}$. The CP20 spectrum looks much more like ASi than CP19 but CP21 and CP22 spectra look much more like the cellulose matrix or like CP19, indicating that the pure cellulose composites accept the inorganic particles up to $43 \mathrm{wt} \%$, while the cellulose matrix modified by solvent-exchange method, AG20, disperses up to $50 \mathrm{wt} \%$ even retaining the cellulose characteristic vibration bands in CP22. Such behavior has been observed in previous works of this working group [21,22]. The high amounts of inorganic nanoparticles and also the particle size dispersed into the AG20 matrix will affect also the thermal stability of the composites.

The weak band in $1635 \mathrm{~cm}^{-1}$ has been related to the fibers water absorption [23]; it was observed in C20, Figure 1, and even with less intensity in AG20, Figure 2, but it is practically not seen in Figure 3, thereby indicating that the fibers' hydrophilic character was dramatically reduced, since hydroxyl groups exposition was hindered by the silica nanoparticles [24].

Some authors suggest that after surface modification of the fibers, the presence of peaks in the region near to 450,800 and $1100 \mathrm{~cm}^{-1}$ indicate that chemical bonding between cellulose and silica nanoparticles is taking place, since the band in $1100 \mathrm{~cm}^{-1}$ is assigned to Si-O-C stretching vibration $[25,26]$. In this study, even when no precursors of the inorganic nanoparticles were used and no crosslinking agent or catalyst was used, the characteristic vibration bands of cellulose and silica were observed in these hybrid composites produced in a facile synthesis way. 


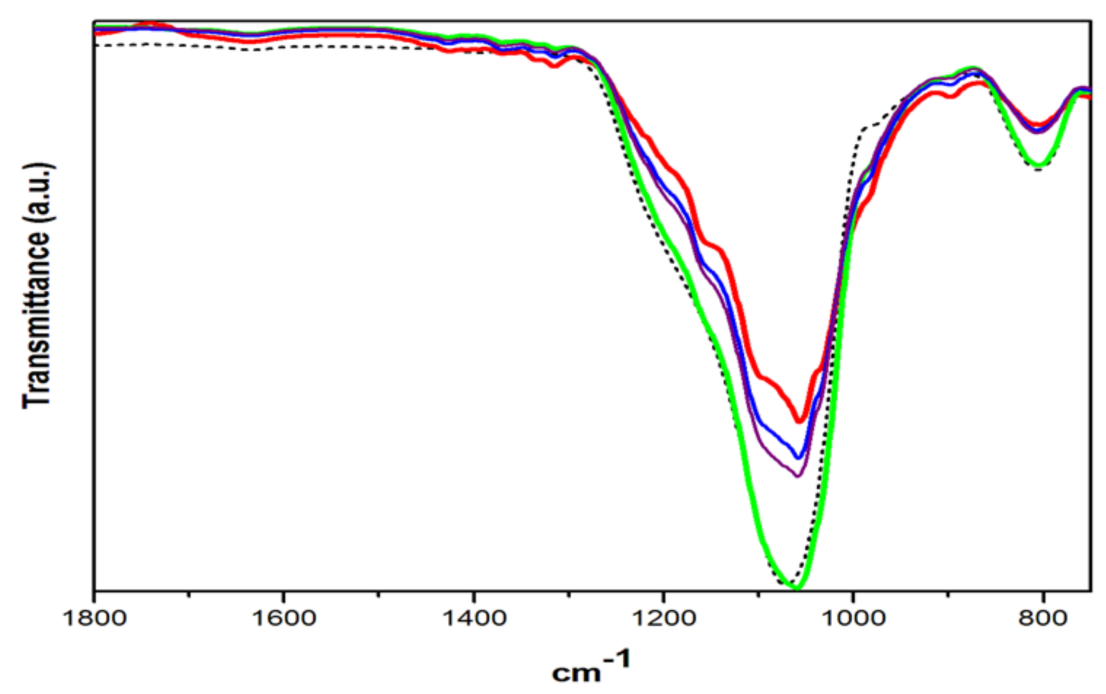

Figure 3. FTIR spectra of ASi (black dash line), CP19 (red line), CP20 (green line), CP21 (blue line) and CP22 (purple line).

\subsection{Scanning Electron Microscopy}

The dispersion of the reinforcers within the matrix C20 and AG20 in the composites was analyzed by scanning electron microscopy. The comparison of micrographs of CP2 vs. CP4 and CP20 vs. CP22 under 100,000 magnifications are shown in Figure 4. The micrograph of CP2 shows an aggregation of well delimited sphere shapes particles that are bigger than $300 \mathrm{~nm}$ while the CP4 micrograph shows, for the same magnification, a more continuous surface of such aggregation of sphere-shaped particles containing the biggest one of $150 \mathrm{~nm}$. This comparison enabled us to consider that using the same quality of reinforcer, $\mathrm{NSi}$, the composite resulting is affected by applying solvent exchange method to the pure matrix. Such a reaction could result in improved embedding of the filler within CP4 matrix, strengthened by the enhanced filler matrix interactions due to the matrix surface modification. However, the particle size distribution of every composite must be measured in the near future in order to clarify how this treatment is affecting the composites. The comparison of CP20 and $\mathrm{CP} 22$ focuses the attention on the effect of particle size since ASi is the filler that shows nearly one-tenth of NSi size. The micrograph of CP20 enabled us to see a more homogeneous distribution of particle size with values of 24 and $55 \mathrm{~nm}$ (not shown in picture) while the CP22 micrograph shows an even more continuous surface indicating that again the modification of the matrix has affected the distribution of filler giving place to a nice continuous morphology. In sum, we can say that using the filler of ASi (12 nm size) is very convenient for producing homogeneous composites when the matrix has been modified by a solvent exchange method such as AG20. Comparing the four composites micrographs allows us to see a progressive plasticizing effect that is clear in CP22 where the matrix is AG20 and the filler is ASi in $50 \mathrm{wt} \%$ content. This effect is very important to notice since no agglutinating resin was added in these composites.

Exactly the opposite effect has been observed in a study of cellulose acetate butyrate (CAB) and cellulose nanowhiskers (CNW) hybrids obtained with nearly the same method used by us. Under $25,000 \times$ the CAB looks neat and smooth on the contrary the nanocomposite containing $12 \mathrm{wt} \%$ of CNW under 50,000 $\times$ shows voids and also dots considered as transversal sections of whiskers embedded in the matrix, the absence of aggregates at micrometer scale confirms the good dispersion of CNWs but no smooth surface or plasticized result is observed in these hybrid materials [27]. 


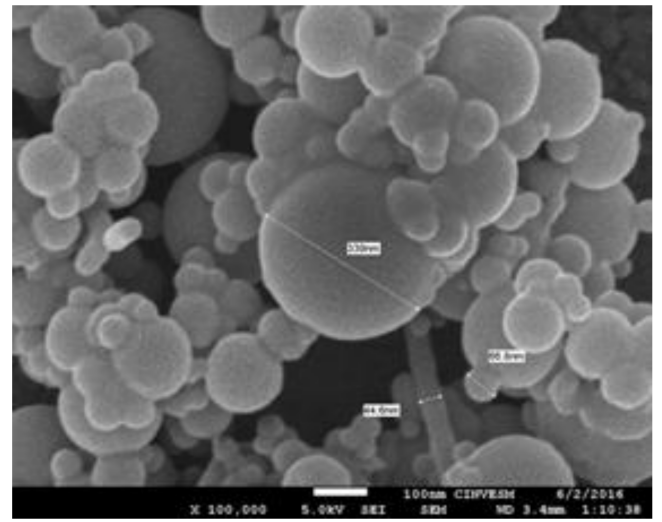

(a)

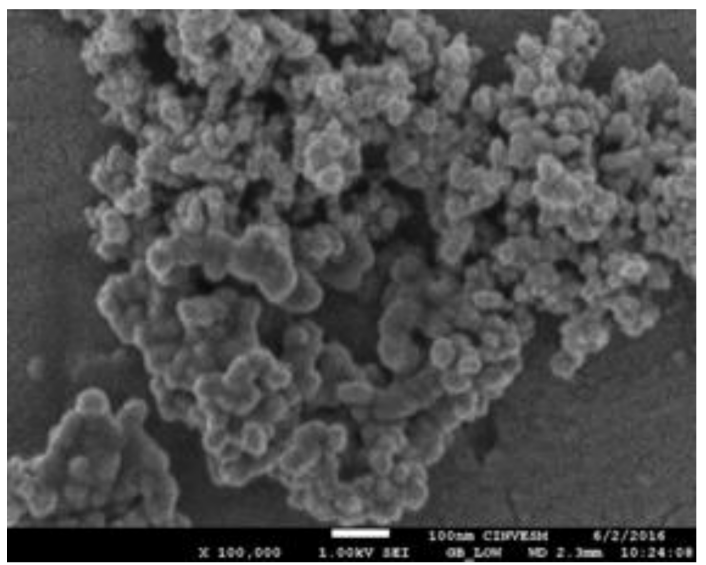

(c)

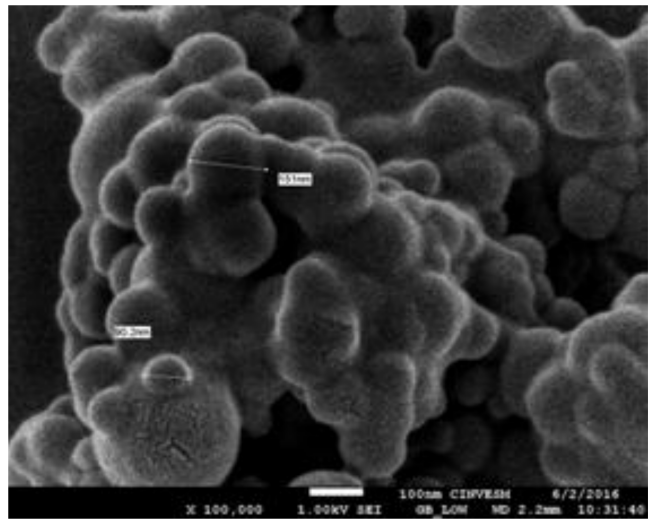

(b)

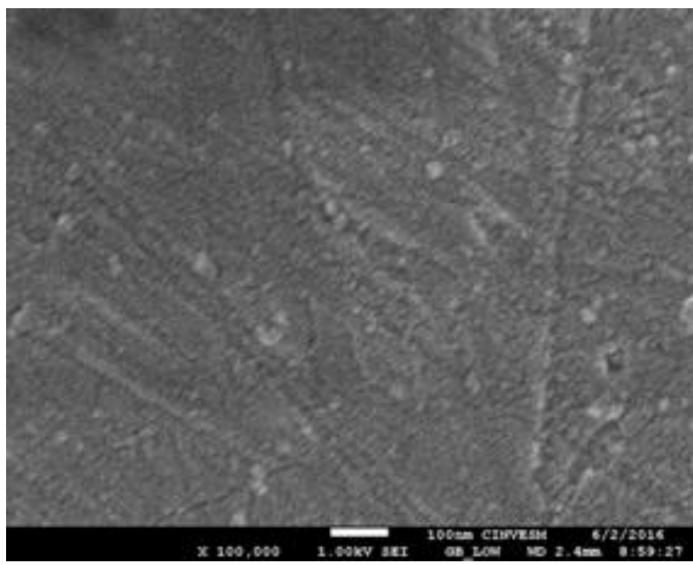

(d)

Figure 4. SEM micrographs of composites at 100,000×. (a) CP2 composite; (b) CP4 composite; (c) CP20 composite and (d) CP22 composite.

\subsection{Thermogravimetric Analysis}

In order to determine the silica content in the composites, TGA measurement was carried out in air. Figure 5 shows the TGA curves of CP2, CP4, CP20 and CP22. In these samples, the thermal degradation occurs mainly at about $324^{\circ} \mathrm{C}$, but the most interesting point is the residual weight remaining at $500{ }^{\circ} \mathrm{C}$. The composite $\mathrm{CP} 20$ of $\mathrm{C} 20$ matrix and ASi reinforcer contains residual weight of $47.3 \%$, that is close to the nominal $50 \mathrm{wt} \%$ remanent according to the formulation indicating that this composite released $2.7 \mathrm{wt} \%$ more than expected. On the other hand, composite CP22 of AG20 matrix and ASi reinforcer contains residual weight of $53.7 \%$ indicating that this formulation retained $3.7 \mathrm{wt} \%$, possibly due to the inorganic particles stabilization into the matrix fibers net. About composite CP2 of C20 matrix and NSi reinforcer according to the formulation $50 \mathrm{wt} \%$ of residual silica content must be expected, but this sample retains only $41 \%$ indicating again that $9 \%$ is released in excess, akin to CP20. In such C20 matrix samples, an excess of mass is released after $500{ }^{\circ} \mathrm{C}$ treatment. On the contrary, composite CP4 of AG20 matrix and NSi reinforcer releases only $38 \mathrm{wt} \%$ retaining $62 \mathrm{wt} \%$, meaning that $12 \%$ more weight is retained in this composite in comparison with the calculated content of silica. An excess of weight is found in the composites of AG20 matrix after $500{ }^{\circ} \mathrm{C}$ treatment as in the case of CP22. An explanation of this large amount of residual mass in $\mathrm{CP} 4$ could relay in the thermal capability of NSi that can be shielding the composite matrix avoiding its complete thermal degradation due to the chemical functionalization of NSi that it is not the case for ASi. 


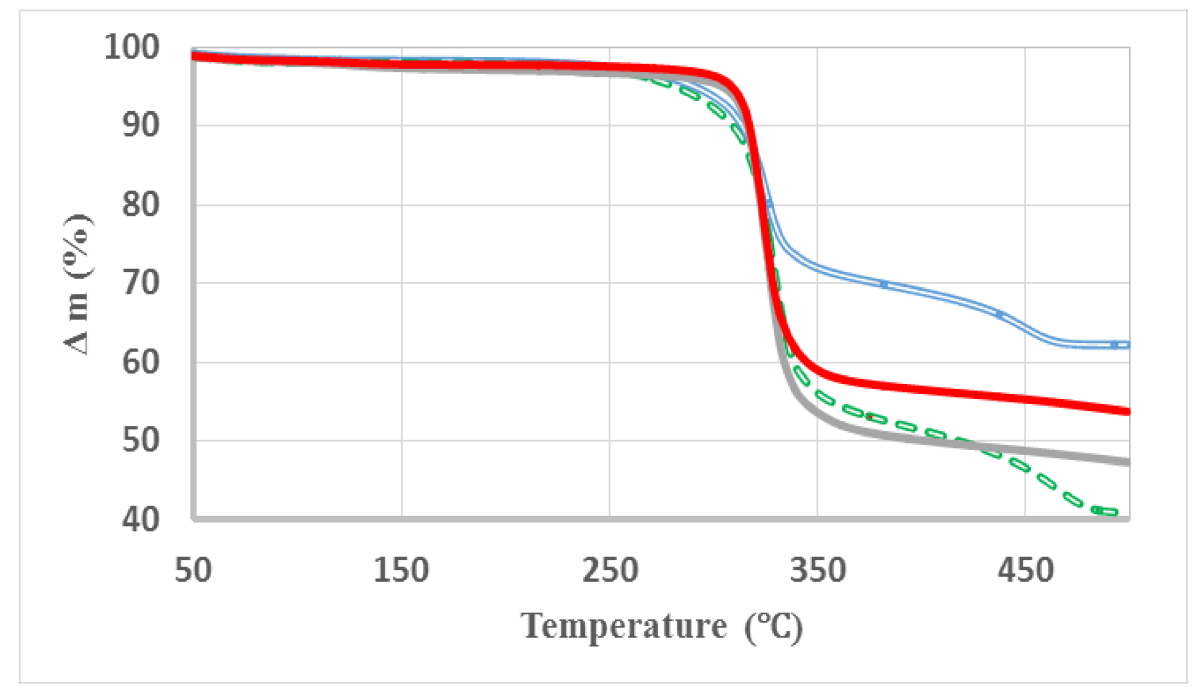

Figure 5. TGA curves of CP2 (green line), CP4 (blue line), CP20 (gray line) and CP22 (red line).

The complete series of composites, 25, 50, 75 and $100 \mathrm{wt} / \mathrm{wt}$, of C20 and AG20 matrix with the same reinforcer NSi was measured. The data comparison indicates that the residual mass amount even at $550{ }^{\circ} \mathrm{C}$ shows a trend from $20 \%$ up to $55 \%$ when $75 \%$ of reinforcer was added, but it differs significantly when the higher amount of filler is contained, $100 \%$, meaning the $50 \%$ of composite total mass; when C20 is the matrix it delivers just $41 \%$ of residual mass while in AG20 matrix it is $62 \mathrm{wt} \%$. Such a result suggests that the matrix treated by solvent exchange method is better stabilized by the reinforcer retaining more mass than the matrix that is just untreated.

Recent studies have been conducted of thermal degradation of pure cellulose microfibrils with no content of hemicelluloses, pectins and lignin informed by TGA and dTGA measurements under nitrogen gas the maximum of thermal degradation at $370{ }^{\circ} \mathrm{C}$, but the complete thermal event starts at 250 finishing at $380^{\circ} \mathrm{C}$ with $16 \mathrm{wt} \%$ of residual mass after $450{ }^{\circ} \mathrm{C}$ [28]. While a study by TGA and dTGA of the same cellulose powder used in this work under the same heating rate shows its maximum thermal degradation at $317^{\circ} \mathrm{C}$, but the complete thermal event takes also from 270 to $340{ }^{\circ} \mathrm{C}$ with a residual mass of $4 \mathrm{wt} \%$ after $420^{\circ} \mathrm{C}$ [29].

About the thermal stability of cellulose/silica hybrid composites, created by a sol-gel method using TEOS precursor of silica, bleached pulp and tungstophosphoric acid $\left(\mathrm{H}_{3} \mathrm{PW}_{12} \mathrm{O}_{40}\right)$ (EPTA). The thermal degradation of the organic material was observed at $305^{\circ} \mathrm{C}$ and at $345-350{ }^{\circ} \mathrm{C}$ for the hybrid materials indicating that with $51 \%(\mathrm{wt} / \mathrm{wt})$ of $\mathrm{SiO}_{2}$ content in the cellulosic composites clearly confers higher thermal resistance to those materials. This communication also relates the thermal conductivity coefficient of these materials with the effect of silica content showing its capacity as conventional insulation material [30].

When using bacterial cellulose (BC) hydrogel for preparing composites with TEOS, the BC hydrogel was immersed into 10 and 20\% aqueous TEOS dispersions delivering silica deposited on BC microfibrils via silanol. The TGA measurements indicated that thermal degradation occurs at $320{ }^{\circ} \mathrm{C}$ and after $500{ }^{\circ} \mathrm{C}$ the silica content was $43 \mathrm{wt} \%$ of the hybrid composite prepared with $20 \%$ TEOS. Those TGA curves look very similar to those of CP2 and CP4 of this work [31].

Another group of data also supports the synergy effect of the synthetic process, that it generates materials with new properties and potential applications. When $\mathrm{SiO}_{2}$ nanoparticles were chemically bonded on the surface of the cellulose fibers the thermal stability of these fibers was improved. Even a reduction of up to $50 \%$ in the moisture adsorption capacity of the modified cellulose fibers was observed $[24,32]$. Although these study hybrid composites were produced by a very facile synthesis, its thermal behavior shows very competitive performance. 


\subsection{Differential Scanning Calorimetry}

The results found by DSC are quite interesting, since it is reported that cellulose pyrolysis shows a clear endothermic peak around $350{ }^{\circ} \mathrm{C}$, but at temperatures higher than $400{ }^{\circ} \mathrm{C}$ exothermal properties of the related reactions in cellulose pyrolysis were observed [33]. In the present study, the effect of reinforce particle size on the same matrix, AG20, is analyzed on CP4 with NSi and CP22 with ASi, see Figure 6. The comparison of C20, AG20 against the composites shows a small endothermic peak around $310{ }^{\circ} \mathrm{C}$ : 306 in C20 and 311 in AG20 while in CP4 no endothermic peak was found but the degradation starts at $225^{\circ} \mathrm{C}$ marking a clear difference with CP22 being the only composite that shows a small exothermic peak with maximum at $300{ }^{\circ} \mathrm{C}$. When the temperature increased the next peak was exothermic, showing a clear shifting from 363 (C20) to 373 (AG20). CP22 and CP4 show that maximum in 347 and 349 , respectively, but the last one also shows a shoulder found at lower temperature, $335{ }^{\circ} \mathrm{C}$. The second exothermic peak shows a similar maximum among the composites and raw material: 505 (CP22), 507 (C20) and 511 (AG20), CP4 shows the maximum in $472{ }^{\circ} \mathrm{C}$ with the highest heat flow of all of them. In contrast, the composite with the lowest heat flow is CP22. The behavior of these composites is consistent with the mass loss observed by TGA measurements. Table 2 features the characteristic thermal events of selected composites and raw materials.

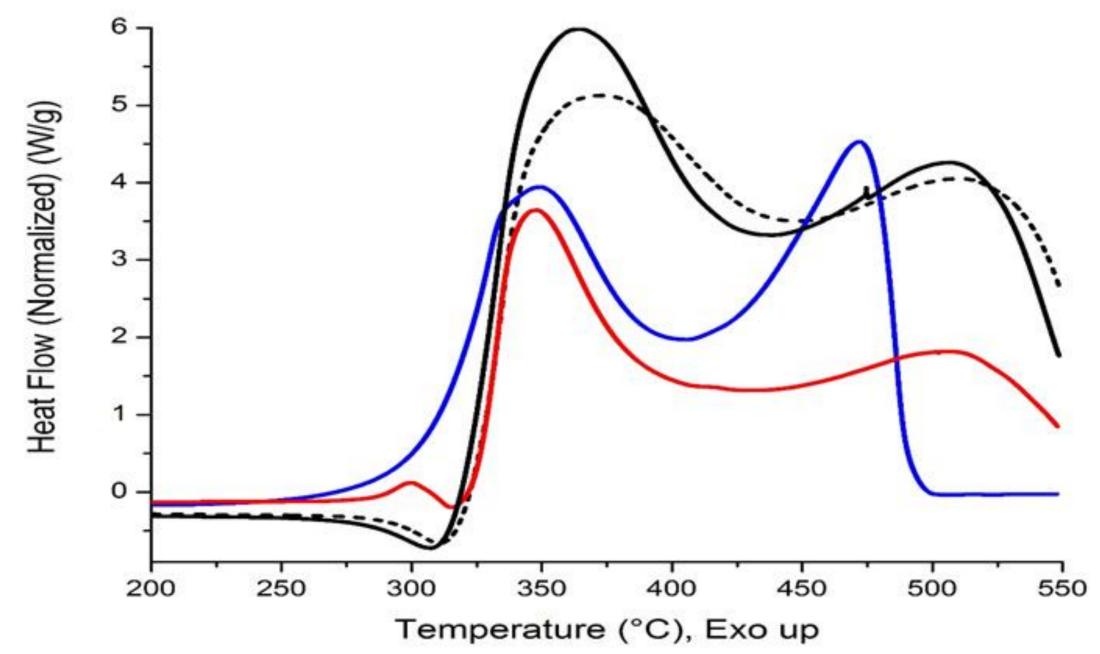

Figure 6. DSC curves of CP4 (blue line), CP22 (red line) versus AG20 (short dash line), C20 (black line).

Table 2. Characteristic features of thermal decomposition of composites.

\begin{tabular}{cccccc}
\hline Sample & $\operatorname{Tstart~}^{\mathbf{1}}\left({ }^{\circ} \mathbf{C}\right)$ & $\operatorname{Tmax}^{\mathbf{1}}\left({ }^{\circ} \mathbf{C}\right)$ & $\operatorname{Tmax}^{\mathbf{2}}\left({ }^{\circ} \mathbf{C}\right)$ & $\operatorname{Tmax}^{\mathbf{2}}\left({ }^{\circ} \mathbf{C}\right)$ & $\operatorname{Mass~Loss~}^{\mathbf{3}}(\mathbf{w t} \mathbf{\%})$ \\
\hline CP2 & 225 & 324 & 350 & 485 & 59.1 \\
CP4 & 223 & 327 & 349 & 472 & 37.9 \\
CP20 & 280 & 325 & 350 & 505 & 52.7 \\
CP22 & 290 & 324 & 347 & 505 & 46.3 \\
AG20 & 250 & 325 & 373 & 511 & 97.0 \\
C20 & 225 & 323 & 363 & 507 & 97.0 \\
\hline
\end{tabular}

${ }^{1}$ by dTGA, ${ }^{2}$ by DSC exothermal peak, ${ }^{3}$ up to $500{ }^{\circ} \mathrm{C}$.

Among other working groups that have studied the degradation process of cellulose by DSC, one group found that degradation already starts at $220^{\circ} \mathrm{C}$, finishing at $475{ }^{\circ} \mathrm{C}$ with total mass loss of $97.6 \%$ [34]. They related the pyrolysis onset temperature by DTA with the cellulose crystallinity index citing the publication of Ciolacu and Popa, when the cellulose shows the lowest crystallinity index the degradation takes place at lowest temperature but the heating rate must be also considered [35]. The solvent exchange treatment brought better thermal stability to AG20 starting its thermal degradation $25{ }^{\circ} \mathrm{C}$ higher than pristine cellulose. 
Another group that employed bleached pulp, TEOS and several catalysts to obtain hybrid materials by sol-gel method found, by TGA and DSC, that as the degree of the silica crosslinking increases the thermal stability of composites increases as well, even though the highest amount of silica incorporated was just $31.3 \% \mathrm{wt} / \mathrm{wt}$. This explains that the endothermic peaks found in the region 310-340 ${ }^{\circ} \mathrm{C}$ correspond to segmental motions in the hybrid materials under degradation [36].

Considering the fact that the sol-gel method suggests covalent bonding between cellulose and silica in hybrids, we believe that no covalent bonding is present in our hybrid materials, since the thermal degradation starts with an exothermic peak in CP22, a rather electrostatic interaction takes place instead; however, dedicated work to clarify this effect is under progress.

\subsection{Trametes Versicolor Resistance}

The antifungal activities of the 4 samples of hybrid composites of CP22 composition were registered according to the ASTM D-1413 standard test method, just pure and with the film of QV 528 over some samples surface. Both images in Figure 7 show the comparison of Trametes versicolor growth on the composites cubes. The $\mathrm{CP} 22$ cube with no QV resin film coat shows no growth of fungi while CP22 with QV resin film shows just little overgrown by the test fungi. However, the weights record demonstrated that such QV resin is preserving the CP22 surface against the fungi attack since CP22 (a) shows a higher decrease of weight, 9\%, while CP22 (b) decreased only $7.3 \mathrm{wt} \%$. We must think about the chemical composition of each resin in order to explain this result. The acryl styrene resin (Joncryl) contains aromatic groups keeping the fungi growing at minimum since aromatics are toxic for the microorganism but the fungi can migrate into the composite bulk through the surface defects [37]. On the other hand, the vinyl acrylic resin $(\mathrm{QV})$ contains aliphatic groups mainly favoring the fungi growth but when the resin film is adhered over the composites surface covering its defects it rejects humidity adsorption preventing the fungi attack. The growth inhibition of Trametes versicolor in these hybrid composites can be related also to its water absorption capability, lower water absorption means lower fungus growth capacity but no water absorption standard test was performed on these composites. The antifungal effect is on the same order that the decay resistance to the same fungus when untreated southern yellow pine particles were blended with $10 \%$ urea formaldehyde resin under the AWPA E10-91 standard test method for solid wood showing weight loss of just $8.1 \%$ of the particle board total weight after 12 weeks exposure [38].

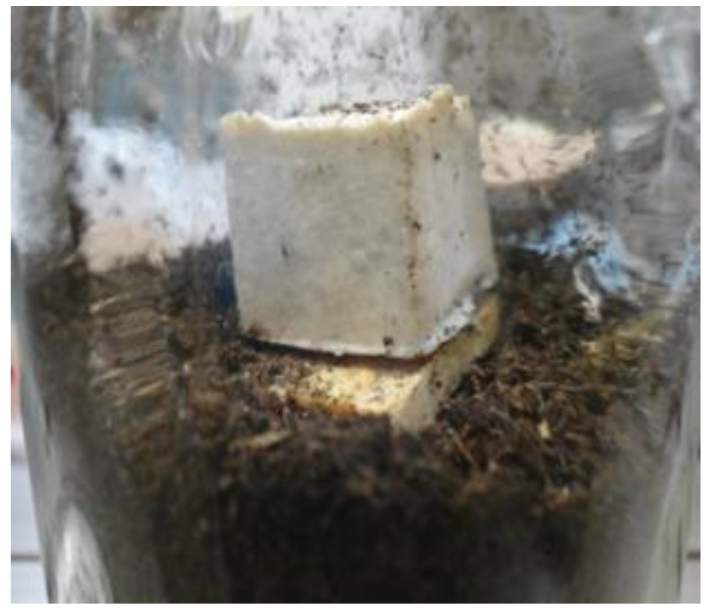

(a)

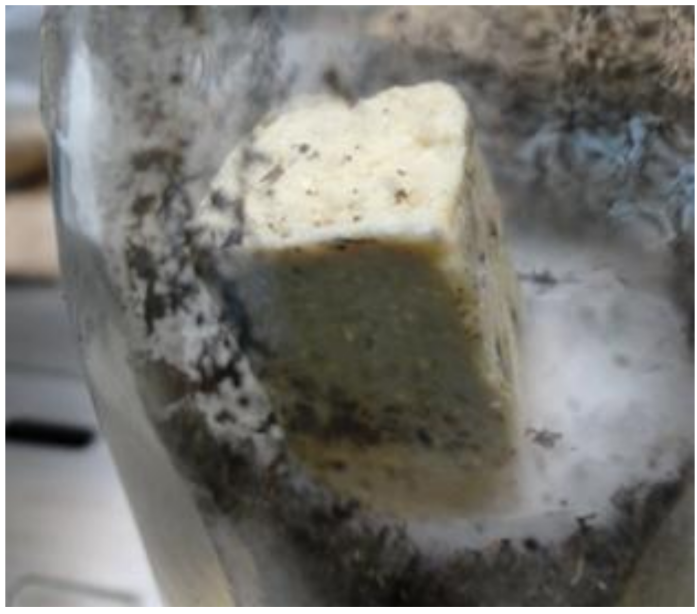

(b)

Figure 7. ASTM D-1413 standard test with Trametes versicolor of (a) CP22 and (b) CP22 with QV resin film.

A comparison of enzymolysis degradation by cellulase of sisal fibers and sisal self- reinforced composites has shown that under cellulose-to-specimen weight ratio of $1 \%$ after $10 \mathrm{~h}$ of reaction the 
composites are less susceptible to enzyme aided biodegradation than the fibers. The buffer solution of cellulase can only immigrate into the composite bulk through surface defects indicating low reaction probability [39].

The same standard test D1413 was applied to wood plastic composites (WPC), specimens prepared by hot press system with $40 \%$ polypropylene and $60 \%$ particles of pine, maple or oak wt/wt. After 12 weeks of Trametes versicolor exposure, the maple samples showed $16 \mathrm{wt} \%$ loss while the oak samples showed $13 \mathrm{wt} \%$ loss [40]. All these cases have shown lower resistance to T. versicolor than the composites prepared by our method.

On the other hand, these kinds of composites could be also used to protect paper artwork from deterioration of Aspergillus versicolor growth applying a thin film of composite to prevent the re-growth of fungi after cleaning the paper surface by microwave heating that has recently been reported by an Italian research group [41].

\section{Conclusions}

An environmentally friendly one-pot method was designed after the percolation approach for avoiding the grafting of molecules to the cellulose surface or the functionalization of the inorganic filler, silica nanoparticles. The key step of this work is using the solvent exchange strategy [42] for not drying the cellulose matrix, keeping the voids of biopolymer net to host the inorganic nanoparticles. The surface modification of cellulose by this method allowed the observation of its macroscopic hydrophobicity providing compatibility with the inorganic reinforcer up to $50 \mathrm{wt} \%$ registered by SEM images. Even when no contact angles of the samples were measured, we can say that the nanocomposite itself shows hydrophobic behavior hindering the fungal growth, thereby demonstrating high capability to use this material in exteriors such as building façades or as thermal insulator fillers, even when the material is not an aerogel.

This facile and cost-effective synthetic method prepares an uncommon kind of nanocomposite, since cellulose from several sources and varied types of particles and sizes are commonly used for reinforcing synthetic polymers [43] or other biopolymers such as starch, but it is not commonly used as matrix, except for all cellulose composites [44]. Also, the simplicity of the applied method opens up the possibility for application in high-volume processes of polymers that nowadays require the ability to withstand higher temperatures.

Acknowledgments: To CONACYT for funding the project PDCPN 215555 also for scholarship given to MCRR. The authors acknowledge the Mexican program PRODEP 2018 for financial support. To Colección Nacional de Cepas Microbianasy Cultivos Celulares CINVESTAV Mexico for the fungal strain. To Santiago González for TGA and DSC measurements. To Lyn Fuchs for style corrections.

Author Contributions: Patricia Ponce-Peña and Martha Poisot conceived and designed the experiments, Martha Poisot wrote the paper. M. Azucena González-Lozano and Guillermo Ramírez-Galicia performed the FTIR measurements and analysis. Patricia Quintana Owen contributed with SEM analysis. Miguel A. Aguilar-González, Georgina Nieto-Castañeda, Elva Bazán-Mora and Rubén López-Martínez contributed with the fungi decay resistance experiments and analysis. M. Concepción Rodríguez-Robledo contributed to the samples-experiments performance.

Conflicts of Interest: The authors declare no conflict of interest.

\section{References}

1. Kakani, S.L.; Kakani, A. Material Science; New Age International Publishers: New Delhi, India, 2006; ISBN 8122415288.

2. Miao, C.; Wadood, Y.; Hamad, W.Y. Cellulose reinforced polymer composites and nanocomposites: A critical review. Cellulose 2013, 20, 2221-2262. [CrossRef]

3. Mansor, M.R.; Sapuan, S.M. Concurrent Conceptual Design and Materials Selection of Natural Fiber Composite Products; Springer Briefs in Materials; Springer: Singapore, 2018; ISBN 978-981-10-6589-7.

4. Saba, N.; Md Tahir, P.; Jawaid, M. A Review on potentiality of nano filler/natural fiber filled polymer hybrid composites. Polymers 2014, 6, 2247-2273. [CrossRef] 
5. Oksman, K.; Mathew, A.P.; Bondeson, D.; Kvien, I. Manufacturing process of cellulose whiskers/polylactic acid nanocomposites. Compos. Sci. Technol. 2006, 66, 2776-2784. [CrossRef]

6. Pickering, K.L.; Aruan Efendy, M.G.; Le, T.M. A review of recent developments in natural fibre composites and their mechanical performance. Compos. Part A 2016, 83, 98-112. [CrossRef]

7. Matthews, F.L.; Rawlings, R.D. Composite Materials: Engineering and Science; CRC Press/Woodhead Publishing: Cambridge, UK, 1999; ISBN 978-1-85573-473-9.

8. Missoum, K.; Belgacem, M.N.; Bras, J. Nanofibrillated cellulose surface modification: A review. Materials 2013, 6, 1745-1766. [CrossRef] [PubMed]

9. Faruk, O.; Bledzki, A.K.; Fink, H.P.; Sain, M. Progress report on natural fiber reinforced composites. Macromol. Mater. Eng. 2014, 299, 9-26. [CrossRef]

10. Singh, B.; Gupta, M.; Verma, A. Influence of fiber surface treatment on the properties of sisal-polyester composites. Polym. Compos. 1996, 17, 910-918. [CrossRef]

11. Cai, J.; Liu, S.; Feng, J.; Kimura, S.; Wada, M.; Kuga, S.; Zhang, L. Cellulose-Silica nanocomposite aerogels by in Situ formation of silica in cellulose gel. Angew. Chem. Int. Ed. 2012, 51, 2076-2079. [CrossRef] [PubMed]

12. Feng, J.; Le, D.; Nguyen, S.T.; Chin Nien, V.T.; Jewell, D.; Duong, H.M. Silica-Cellulose hybrid aerogels for thermal and acoustic insulation applications. Colloids Surf. A 2016, 506, 298-305. [CrossRef]

13. Ramesh, S.; Kim, J.; Kim, J.-H. Characteristic of Hybrid Cellulose-Amino functionalized POSS-Silica nanocomposite and antimicrobial activity. J. Nanomater. 2015, 2015, 936590. [CrossRef]

14. Capadona, J.R.; Van Den Berg, O.; Capadona, L.A.; Schroeter, M.; Rowan, S.J.; Tyler, D.J.; Weder, C. A versatile approach for the processing of polymer nanocomposites with self-assambled nanofibre templates. Nat. Nanotechnol. 2007, 2, 765-769. [CrossRef] [PubMed]

15. Eichhorn, S.J.; Dufresne, A.; Aranguren, M.; Marcovich, N.E.; Capadona, J.R.; Rowan, S.J.; Weder, C.; Thielemans, W.; Roman, M.; Renneckar, S.; et al. Current international research into cellulose nanofibres and nanocomposites. J. Mater. Sci. 2010, 45, 1-33. [CrossRef]

16. ASTM D1413-07. Standard Test Method for Wood Preservatives by Laboratory Soil-Block Cultures; American Society for Testing and Materials: West Conshohoken, PA, USA, 1999.

17. Marechal, Y.; Chanzy, H. The hydrogen bond network in Ibeta cellulose as observed by infrared spectrometry. J. Mol. Struct. 2000, 523, 183-196. [CrossRef]

18. Kondo, T.; Sawatari, C. A Fourier transform infra-red spectroscopic analysis of the character of hydrogen bonds in amorphous cellulose. Polymer 1996, 37, 393-399. [CrossRef]

19. Rodríguez-Díaz, J.M.; Prieto García, J.O.; Bravo Sánchez, L.R.; da Silva, M.G.C.; da Silva, V.L.; Arteaga-Pérez, L.E. Comprehensive characterization of sugarcane bagasse ash for its use as an adsorbent. BioEnergy Res. 2015, 8, 1885-1895. [CrossRef]

20. Criado, M.; Aperador, W.; Sobrados, I. Microstructured and mechanical properties of alkali activated Colombian raw materials. Materials 2016, 9, 158. [CrossRef] [PubMed]

21. Rodríguez-Robledo, M.C. Compositos Híbridos de Matriz Celulósica y Reforzantes Inorgánicos. Master's Thesis, Universidad del Papaloapan, San Juan Bautista Tuxtepec, Mexico, 1 June 2017.

22. Vásquez-Zacarías, L. Estudio del Desempeño de Compositos Híbridos de Matriz Celulósica. Master's Thesis, Universidad del Papaloapan, San Juan Bautista Tuxtepec, Mexico, 15 March 2017.

23. Ashori, A.; Sheykhnazari, S.; Tabarsa, T.; Shakeri, A.; Golalipour, M. Bacterial cellulose/silica nanocomposites: Preparation and characterization. Carbohydr. Polym. 2012, 90, 413-418. [CrossRef] [PubMed]

24. Raabe, J.; de Souza Fonseca, A.; Bufalino, L.; Ribeiro, C.; Martins, M.A.; Marconcini, J.M.; Denzin, G.H. Evaluation of reaction factors for deposition of silica $\left(\mathrm{SiO}_{2}\right)$ nanoparticles on cellulose fibers. Carbohydr. Polym. 2014, 114, 424-431. [CrossRef] [PubMed]

25. Naghsh, M.; Sadeghi, M.; Moheb, A.; Chenar, M.P.; Mohagheghian, M. Separation of ethylene/ethane and propylene/propane by cellulose acetate-silica nanocomposite membranes. J. Membr. Sci. 2012, 423-424, 97-106. [CrossRef]

26. Lu, T.; Jiang, M.; Jiang, Z.; Hui, D.; Wang, Z.; Zhou, Z. Effect of surface modification of bamboo cellulose fibers on mechanical properties of cellulose/epoxy composites. Compos. Part B Eng. 2013, 51, 28-34. [CrossRef]

27. Siqueira, G.; Mathew, A.P.; Oksman, K. Processing of cellulose nanowhiskers/cellulose acetate butyrate nanocomposites using sol-gel process to facilitate dispersion. Compos. Sci. Technol. 2011, 71, 1886-1892. [CrossRef] 
28. Quiévy, N.; Jacquet, N.; Sclavons, M.; Deroanne, C.; Paquot, M.; Devaux, J. Influence of homogenization and drying on the thermal stability of microfibrillated cellulose. Polym. Degrad. Stab. 2010, 95, 306-314. [CrossRef]

29. Soares, S.; Caminot, G.; Levchik, S. Comparative study of the thermal decomposition of pure cellulose and pulp paper. Polym. Degrad. Stab. 1995, 49, 275-283. [CrossRef]

30. Sequeira, S.; Evtuguin, D.V.; Portugal, I. Preparation and properties of cellulose/silica hybrid composites. Polym. Compos. 2009, 30, 1275-1282. [CrossRef]

31. Maeda, H.; Nakajima, M.; Hagiwara, T.; Sawaguchi, T.; Yano, S. Bacterial cellulose/silica hybrid fabricated by mimicking biocomposites. J. Mater. Sci. 2006, 41, 5646-5656. [CrossRef]

32. Shi, J.; Lu, L.; Guo, W.; Zhang, J.; Cao, Y. Heat insulation performance, mechanics and hydrophobic modification of cellulose-SiO2 composite aerogels. Carbohyd. Polym. 2013, 98, 282-289. [CrossRef] [PubMed]

33. Yang, H.; Yan, R.; Chen, H.; Lee, D.H.; Zheng, C. Characteristics of hemicellulose, cellulose and lignin pyrolysis. Fuel 2007, 86, 1781-1788. [CrossRef]

34. Szczesniak, L.; Rachocki, A.; Tritt-Goc, J. Glass transition temperature and thermal decomposition of cellulose powder. Cellulose 2008, 15, 445-451. [CrossRef]

35. Ciolacu, D.; Popa, V. On the thermal degradation of cellulose allomorphs. Cell Chem. Technol. 2006, 40, 445-449.

36. Sequeira, S.; Evtuguin, D.V.; Portugal, I.; Esculcas, A.P. Synthesis and characterisation of cellulose/silica hybrids obtained by heteropoly acid catalysed sol-gel process. Mater. Sci. Eng. C 2007, 27, 172-179. [CrossRef]

37. Ander, P.; Hatakka, A.; Eriksson, K.-E. Vanillic acid metabolism by the white-rot fungus Sporotrichum pulverulentum. Arch. Microbiol. 1980, 125, 189-202. [CrossRef]

38. Kartal, S.N.; Clausen, C.A. Leachability and decay resistance of particleboard made from acid extracted and bioremediated CCA-treated wood. Int. Biodeterior. Biodegrad. 2001, 47, 183-191. [CrossRef]

39. Lu, X.; Zhang, M.Q.; Rong, M.Z.; Yue, D.L.; Yang, G.C. Environmental degradability of self-reinforced composites made from sisal. Compos. Sci. Technol. 2004, 64, 1301-1310. [CrossRef]

40. Lomeli-Ramirez, M.G.; Ochoa-Ruiz, H.G.; Fuentes-Talavera, F.J.; Garcia-Enriquez, S.; Cerpa-Gallegos, M.A.; Silva-Guzman, J.A. Evaluation of accelerated decay of wood plastic composites by Xylophagus fungi. Int. Biodeterior. Biodegrad. 2009, 63, 1030-1035. [CrossRef]

41. Cerchiara, T.; Palermo, A.M.; Esposito, G.; Chidichimo, G. Effects of microwave heating for the conservation of paper artworks contaminated with Aspergillus versicolor. Cellulose 2018, in press. [CrossRef]

42. Espino-Perez, E.; Domenek, S.; Belgacem, N.; Sillard, C.; Bras, J. Green process for chemical functionalization of nanocellulose with carboxylic acids. Biomacromolecules 2014, 15, 4551-4560. [CrossRef] [PubMed]

43. Lee, K.-Y.; Aitomäki, Y.; Berglund, L.A.; Oksman, K.; Bismarck, A. On the use of nanocellulose as reinforcement in polymer matrix composites. Compos. Sci. Technol. 2014, 105, 15-27. [CrossRef]

44. Wang, Y.; Chen, L. Impacts of nanowhisker on formation kinetics and properties of all-cellulose composite gels. Carbohydr. Polym. 2011, 83, 1937-1946. [CrossRef]

(c) 2018 by the authors. Licensee MDPI, Basel, Switzerland. This article is an open access article distributed under the terms and conditions of the Creative Commons Attribution (CC BY) license (http:/ / creativecommons.org/licenses/by/4.0/). 